\title{
Comparing Role Playing and Lecture Training in Use of Permethrin Shampoo, On Pediculosis Treatment of Elementary School Girls
}

Tayebeh Samieizadeh Toosi*

Department of Public Health, Shahid Beheshti University of Medical Sciences, Tehran, Iran

\begin{abstract}
Introduction: The development of a society depends on public health of its people. In cases threatening public health, external parasites is still a health problem arises. Prevalence of head lice in children 6-12 years and primary schools developed countries is 10.2 percent. On the other hand there is also a problem in developing countries shampoo permethrin in the treatment of head lice are commonly used, often by health care providers were available, patients are taught how to use it. This study aimed to compare the effect of role playing and lectures on how to use permethrin shampoo on the treatment of female primary school students with Pediculosis was Iranshahr.
\end{abstract}

Methods: This study was semi-experimental clinical trial in which 500 students with Pediculosis girls' primary schools in six districts of the city of Iranshahr participated and were randomly assigned to two groups of 250 lectures and role shampoos containing permethrin consumption by health experts schools were taught in classes of 10 students. Questionnaire Include questions about individual and family behavior, demographic, and health documents of interviews of students completed. After two weeks of treatment, subjects in the examination and comparison of the results in the two groups were recorded in a questionnaire. All $18 \mathrm{spss}$ software using descriptive and inferential statistics (frequency and percentage) $\mathrm{t} T$ test and chi-square tests were analyzed.

Results: Students with an average age of 50/1 $\pm 05 / 9$ year, most of them first-grade $8 / 21 \%$ and their average $31 / 2 \pm$ $4 / 17$ respectively. The two groups in terms of level of education, father's occupation, parents' education, income, length of hair, itching, hair, bathe and comb woman hair were not significantly different times and were equal. Two weeks after using the shampoo treatment in the Department of roles $5 / 71 \% 5 / 28 \%$ and lecture groups and the chi-square test, this difference was significant too $(p=0 / 00)$.

Conclusion: Educational method greatly contributes to more effective use shampoo permethrin in lice treatment is speech. Better school health educators in their educational programs, from dynamic and consistent with the goal of changing behavior that provokes active participation of learners in the learning process use. Role Playing use shampoo anti-lice used to training in the treatment of head lice in schools achieved better results.

Keywords: Education; Pediculosis; Role playing; Lecture

\section{Introduction}

Ectoparasites such as lice can be a Chvntyfvs because transmission of disease, relapsing fever and has long been of interest to researchers $[1,2]$ Head Lice Head lice or pollution is a major health problem worldwide, communities and is not limited to one continent or community. In all developed countries, developing and developed countries hold different ratios; the contamination or Pdyklvz Kapytys by a human head lice occur and one of the most common health problems of American. The most common head lice prevalence of the infection in children that 6-12 million people suffer [3]. Because head lice do not have any natural enemies, so the only factor that controls the actions of an infected person to remove pollution Therefore, in former times for Mubarak chord with physical methods such as lice comb, remove the insect from among the hair or shaving was used. Seems to use other methods, including the use of synthetic drugs, bath, health education, lack of sharing of personal items, isolation of infected people and also very helpful. Pollution in European countries, Poland [4] Germany [5], American, European, such as Argentina [6], Brazil [7], Colombia [8] United States [3], Canada [9] and Asian countries such as Turkey [10] and African such as Nigeria [11], Korea [12], India [13] and other countries have been reported. Despite preventive activities in developing countries head lice infestation at different ages, pollution still exists and has a higher percentage of children than adults are Lvdhmy [14]. The highest rate of infection in children aged 6-12 years and in girls than boys and in whites than blacks to be observed. Of course, there are reports that schools in high pollution have been reported [15]. The prevalence of poor children and developed countries receive health care under the standard is higher [6] the direct contact with the head is the most common mode of transmission of infection [3]. In addition to direct contact with an infected person louse infestation, head of personal items such as combs, hats, scarves, underwear and towels are considered [16], because lice feed on host blood several times a day, your saliva repeatedly to host the injection of a toxic effect that can cause fatigue, irritation, pessimism and feeling lazy and cause allergies and severe pruritus [9]. Pdyklvz head remains confined to the scalp is itching Serik from its main symptoms, although in some cases may be asymptomatic [2] increased body temperature, headache, feeling of heaviness members, muscle rigidity, insomnia, misbehavior, the incidence of mental problems, lack of concentration in class can be seen particularly in children $[17,18]$ psychological effects of head lice infestation is more than happiness, health, titles and labels

*Corresponding author: Tayebeh Samieizadeh Toosi, Department of Public Health, Shahid Beheshti University of Medical Sciences, Tehran, Iran, Tel: +98 212243 9770; E-mail: samieizadeht@gmail.com

Received December 10, 2017; Accepted December 15, 2017; Published December 20, 2017

Citation: Toosi TS (2017) Comparing Role Playing and Lecture Training in Use of Permethrin Shampoo, On Pediculosis Treatment of Elementary School Girls. J Health Educ Res Dev 5: 241. doi: 10.4172/2380-5439.1000241

Copyright: @ 2017 Toosi TS. This is an open-access article distributed under the terms of the Creative Commons Attribution License, which permits unrestricted use, distribution, and reproduction in any medium, provided the original author and source are credited. 
that are given to individuals, on their ability to perform activities of life negative effects [19]. In some of the states after diagnosis, the student is expelled from school temporarily, this can lead to academic failure [20]. pediculosis capitals in all parts of the world including Iran, especially in areas with high population density associated with poverty and lack of personal hygiene can be seen in abundance. A review in the port of Anzali among elementary school students showed that the prevalence of head lice infection rate of $6.2 \%$ in girls than boys [21]. In a study in the area of Khomeini city Jouyabad, head louse infestation rate was $11.9 \%$ [22]. Pediculosis prevalence in different parts of the country from 30 to $6 \%$ have been reported [23].

Sistan-Baluchistan province by having hot and dry weather and high population density, environment suitable for lice is overpopulation. Akbarzada done in this area in the town of Iranshahr examination of the prevalence of lice and nits elementary schools in urban areas $3 / 29 \%$ and in rural areas it $6 / 57 \%$ earned. He stressed that epidemiological studies can determine the status of contamination, determine its relationship with environmental factors, and then suggest the best way to control it $[24,25]$. Permethrin shampoo to treat head lice using a method that is used. The drug is recommended as the drug of choice and as shampoo, liquid shampoo, powder, lotions and creams available in the market. Also in the study by Mathias, Dinapoli and was Brundenburg, It was shown that $1 \%$ permethrin cream is most effective with high safety and it can be made available without a prescription in the patients [2628]. How permethrin shampoo your hair is first moistened with water and then with shampoo or hair shampoo $1 \%$ are completely soaked. These derivatives are not toxic and has a residual effect on the hair and the hair stays up to 1 week And the envy of the lethal effect have recommended the review and a reassessment of the viability of problem a week later treatment be repeated $[29,30]$. This shampoo is commonly used by health care providers available to patients located and how to use it taught is.

Among the most common and most traditional teacher-centered teaching methods, lecture. Lecture on the advantages, cost-effectiveness, provide regular and direct and logical, skills enhancement, speech teacher and students take notes, has some disadvantages, In which a passive teaching methods and to teach practical skills and mental skills in high levels of learning is not appropriate And does not consider individual differences. In addition, the possibility of early dementia, there are training materials for clients [31]. Role training method that has gained importance and public acceptance, especially when this method of teaching skills should be exhibited in a natural position, without any artificial mode is executed and an individual or small group can be expected on stage for the presentation behavior of different people or different responsibilities play a role [32]. In this comprehensive method to resolve an issue with the use of various views of the innovative presentation and it obtains the issue. From the distinctive features of the role that observers and actors interact with self-view function in the real feel [33].

Since the control and treatment of pediculosis lice shampoo is effective but reportedly expressed Control Center School Health Network Iranshahr to the treatment of this disease is incomplete So, we decided to spread due to excessive pollution in the primary school age group as well as the possibility of change In the traditional approach to education and how to use this study to compare the effect of shampoo and traditional role in Use permethrin shampoo on the treatment of female primary school students do Iranshahr.

\section{Methods}

The experimental clinical trial study was that the community elementary school students with lice in Iranshahr in 90-91 after obtaining permission and consent was dean of the faculty and school administrators. Simple random sampling method and sample size initially by pilot study and implement training on two groups of 60 people obtained 30 considering the significant level of $0 / 05$, the final sample size for each group was as follows: 247 of which 250 were considered.

$$
\begin{aligned}
& \mathrm{N}=(\mathrm{Z} 1-\mathrm{a} / 2+\mathrm{Z} 1-\beta) 2\left(\mathrm{P}_{1}\left(1-\mathrm{P}_{1}\right)+\mathrm{P}_{2}\left(1-\mathrm{P}_{2}\right)\right)=247=250 \\
& \left(\mathrm{P}_{1}-\mathrm{P}_{2}\right) 2 \\
& \mathrm{P}_{2}=0 / 66 \\
& \mathrm{Z} 1-\beta=1 / 64 \\
& \mathrm{P}_{1}=0 / 33
\end{aligned}
$$

Students affected areas of girls' primary schools four children, were randomly selected from the list of schools in Iranshahr. The city of Iranshahr in terms of the elementary school was divided into 6 classes a class of elementary schools of northwest, northeast of elementary school second floor, third floor of the elementary schools of the city center, fourth floor southwestern elementary school, fifth floor, and the sixth floor of south-eastern and southern schools. After each class, some schools were selected randomly so the school girls' primary schools in Iranshahr 6 ( 6 episodes city) the willingness (as well as provide written consent from their parents) to participate in the study and hypersensitivity, erythema and by taking antibiotics during the study were economic and social - were selected almost at a level equal And then randomly divided into two groups of the role that each 250 students, were divided. Then, through role-play for "about" and speaking to groups of "control" was considered by health experts that schools did not know the purpose of this study was performed. The instrument used in this study included a questionnaire for demographic data and tools to identify cases involving alcohol, white $70 \%$, flashlight, disposable gloves, fine-tooth comb, lens, hand, mouth mask and shampoo, permethrin was approved by the Ministry of Health Is. The number of 250 students from first grade to fifth-grade samples with each group randomly from the list of students were selected by lottery. The questionnaire included demographic information as well as 19 questions of individual and family behavior, was the study found that the validity of $C V R=0 / 75$ and is expressed as $C V I=0 / 80$ and $0 / 78$ reliability coefficient calculated Cranach's alpha test shall return. See of student health records (available in health centers) and the interview was obtained. Then play a role in teaching methods, training of health experts was that the students divided into groups by grade separation member 10_6, How to use the shampoo frequency and the amount of it on one of the students enforcement operations and then students from two in two ways shampooing on a virtually "made a running time of Role Playing 20 minutes. Methods speaking in the control group were administered separately which means the Health Center in groups of 10 students divided into separate academic foundation for students then explained how to use permethrin shampoo Shdmdt runtime was 20 minutes lecture. To search across all groups, after two weeks and patients were examined again go to school, and then the results in the two groups were recorded. 17 SPSS and analyzed using descriptive statistical tests (mean and standard deviation) and independent $\mathrm{T}$ test and chi-square test was used to compare the frequencies and quantitative variables. A limitation of this study, environmental factors such as noise and physical environments that help school officials were under control. 


\begin{tabular}{|c|c|c|c|c|c|c|c|}
\hline \multirow{2}{*}{ Methods of Teaching } & \multicolumn{3}{|c|}{ Role playing } & \multicolumn{3}{|c|}{ Lecture training } & \multirow{2}{*}{ p-value } \\
\hline & Number & Average & SD & Number & Average & SD & \\
\hline Age & 250 & 9.16 & 1.48 & 250 & 8.94 & 1.51 & 0.108 \\
\hline Grade point Average & 250 & 17.45 & 2.42 & 250 & 17.5 & 2.21 & 0.773 \\
\hline The number of people living together & 249 & 4.11 & 1.81 & 250 & 3.98 & 1.68 & 0.428 \\
\hline
\end{tabular}

Table 1: Distribution of age, grade point average, the number of people who live together in groups and lectures role in primary schools Iranshahr.

\begin{tabular}{|c|c|c|c|c|c|c|c|}
\hline \multirow{2}{*}{ Methods of Teaching } & \multicolumn{3}{|c|}{ Roleplaying } & \multicolumn{3}{|c|}{ Lecture training } & \multirow{2}{*}{$p$-value } \\
\hline & Number & Percent & Total & Number & Percent & Total & \\
\hline Cured & 176 & 71.5 & & 70 & 28.5 & & $P=0.000$ \\
\hline Not cured & 74 & 29.2 & & 179 & 70.8 & & $\begin{array}{c}X^{2}=89.250 \\
D f=1\end{array}$ \\
\hline
\end{tabular}

Table 2: Distribution of treatment in both groups, role playing and presentations in elementary schools Iranshahr.

\section{Results}

0/021/8 first-grade students, $20 / 8$ second grade elementary\%, 0/021/6 third grade, 0/018/4 in fourth grade and 0/017/4 were in fifth grade. $0 / 050 / 8$ of schools had a health educator. In general, the fathers 0/020/8 unemployed, $0 / 019$ of workers, $0 / 040$ and $0 / 020$ of employees were released. 0/088/5 housewives and 0/012/5 were employed. The Group's role in the lecture group 78/30/089/8 were housewives and the most significant difference between the two groups called the chisquare test Shendo.

0/020 illiterate fathers, 23/8 elementary\%, 0/022/4 tips and 0/033/8 of high school and higher. Most high school and higher. School play group 0/055/4 and in the lecture group 0/053/6 and higher secondary school and two group's most chi-square test, there was no significant difference in terms of education Father. 0/034 of mothers were illiterate, 30/8 elementary\%, 16/4 tips $\%, 0 / 018 / 2$ secondary and higher. More mothers were illiterate. The role of school groups 0/051/2 52/7 and group presentations and two groups of high school and above the maximum amount of the chi-square test, there was no significant difference in terms of maternal education. 0/098 of mothers were still alive. Role in 0/050/5 and speeches 0/049/5 of mothers alive was observed in two groups according to the chi-square test, there was no significant difference in terms of mother alive.

0/040 of households had an income of between three to six hundred dollars. 0/058 had no role in revenue and earnings over six hundred thousand dollars 59/2 lecture group and two groups according to the chi-square test, there was no significant difference in terms of revenue. The number of siblings $4 / 05 \pm 1 / 75$ and, according to two independent samples t-test was no significant difference in the number of family members. 0/046/6 of families had a history of lice. Play a role in $0 / 053$ and 0/046 speech with families and groups in the chi-square test, there was no significant difference in terms of getting the family.

Information in relation to age, grade point average, the number of people who live together in groups and lectures role in primary school Iranshahr in Table 1 is statistically as well as the results obtained Chi In both groups, the grade is shown in Table 2 have been mentioned. The treatment also play a role in the family since $0 / 050 / 2$ in group lectures $0 / 049 / 8$ do not treat the two groups in accordance with the chi-square test, both in terms of treatment, there was no significant difference in families. Role in 0/056/08 and speeches 0/043/2 had undergone previous treatment. And two groups according to the chi-square test, there was no significant difference in the family of previous treatments. A hair itching to play a role in $0 / 050 / 9$ and speeches $0 / 049 / 1$ were itching hair and two groups according to the chi-square test, there was no significant difference in terms of itchy hair. Comb the hair of a woman's role in 0/053/9 and more per day twice daily comb and in the lecture group 0/055/6 did not have a woman's shoulder, but the two groups work according to two tests, significant differences in terms of shoulder woman did not exist. The length of the hair in the role of 0/055/1 and in the lecture group 0/044/9 have had long hair. In terms of the bathing role in $0 / 051 / 2$ and speeches $0 / 050 / 4$ have a bath twice a week. And the Chi-square test for the two groups there was no significant difference shower in a week. Distribution of hair in both groups during role playing and lectures in primary schools shows Iranshahr. After using the shampoo and treatment over the course of two weeks in group play $0 / 071 / 5$, and in speeches $28 / 5$ percent. And two groups according to the chi-square test, the full benefit of taking a significant difference error value equal to 0.05 . Between levels of education, father's occupation, income, father's education, mother's education, live mother, family history, family therapy at the same time and length of hair in conjunction with treatment success rates did not exist. The bathing frequency and amount of therapy significantly associated with chi-square test was 0.05 times the amount of error, in a way that $54 / 3$ was people who bathe twice a week had the highest rate of treatment. Between family members and previous treatment success rate of therapy $(\alpha=0.05)$ there. The itchy hair and the therapy statistically significant chi-square test $(\alpha=0.05)$ was, in a way that $63 / 1$ percent of people who had the highest rate of treatment had the itch hair. As well as between the shoulder and the therapy there was a woman hair day So that 57/4 percent of people who have had two or more times daily comb the hair, the treatment had the highest rate $(\alpha=0.05)$. The T-Test test two groups in age, grade point average, the number of people who live together are not significantly different. Two weeks after using the shampoo in role playing group was more statistically significant according to the chi-square test.

\section{Discussion}

With regard to the relationship between learning how to use shampoo with permethrin results indicated that treatment success rates That play a role in the Therapy group was significantly more than the lecture group was.

Navels et al. in their study similar results were achieved. The mean scores from the Test team after playing 1/73, 1/60 was more than lecture group [28]. Margalit interactive (role) method to education (lectures and pamphlets), knowledge, self-esteem and attitudes toward patientcentered, in medicine [29]. McLaren using this method of knowledge, 
ability to execute management in children will increase in nursing students [30].

Hazavehei, in their study on the effect of educational lectures and games and role playing on knowledge and the performance of students tips on nutrition during puberty and found that the increased role of knowledge in the group more than the lecture group As well as consistency of practice in a significant role and was playing over the speakers. He writes the persistence of higher learning in role-playing method, and it provides the perfect backdrop for participation in education makes more inclusive [27]. Given that in this study, using role playing and lectures to teach you how to use the anti-lice shampoo is used It can be said that students learn better in group play and how to use shampoo. In its application, or in other words, their performance was stronger than the lecture group that the treatment was higher in this group. The impact study also Parvizy child to child education in the field of individual health education on students in Tehran The mean scores consciousness immediately and one month after the training the students group games and was playing over the speakers [27]. In considering confounding factors in the treatment, the results showed a significant relationship between the level of education, occupation and education of parents, income, living mother, Income, living mother, family history of breast cancer, both in the family and in our hair during treatment success rates and there But the itch hair, bathe and comb frequently with the woman and family therapy there was a previous infection. These results represent an important impact on the treatment of personal hygiene is Pediculusis As $1 / 63$ percent of people who were itching hair had the highest rate of treatment, the study tall (1388) statistically between exposure to head lice and itching in the head there was a significant relationship $(0 / 001>P)$ [31]. During the survey Rafinejad (1385) the proportion of subjects with head lice in people who feel itchy had $6 / 3 \%$. In contrast, people who feel itchy at no $0 / 3 \%$. This difference was statistically significant, is. $(0 / 0001>\mathrm{P})$. Also, the daily comb your hair daily and there is a cure so that $57 / 4$ percent of people who have two or more times daily comb the hair. The highest prevalence and treatment of Venice noted a daily comb $(0 / 05>\mathrm{P})$ No significant difference was observed [32]. The bathing frequency and amount of therapy there was a significant association chi-square test, in a way that $54 / 3$ was people who bathe twice a week had the highest rate of infection among students at home. In the study tall bathroom active, $9 / 7 \%$ of the people who live in the house had no bathroom, $38 / 9 \%$ respectively, the difference was statistically significant $(0 / 001 />\mathrm{P})$. Read between the bathroom and there was a significant difference in infection rate $(0 / 05>\mathrm{P})$ [31]. But the study found that the frequency Rafinejad bathroom and there is no significant difference in infection rate $(0 / 083=\mathrm{P})$ [32]. The present study differences in how research studies are listed so that all people are under study with Pediculusis. Also related to previous treatment with shampoo and how the family can use the student's previous knowledge is that it also shows the importance of individual training in the treatment. In this Rafinejad of infection in children with short hair, medium and long term respectively $7 / 7 \%$, $11 / 4 \%$ and $21 \%$, respectively. The $56 / 2 \%$ of students were infected in other family members [32]. In a study tall between prevalence and length of hair was a significant difference $(0 / 001>\mathrm{P})$ [31]. In this Farzinnia (1383) in Qom significant relationship between short or long hair and pediculosis capitis in primary school students in Qom were girls $(0 / 05>\mathrm{P})$ in the imagine that among patients with long hair role in $1 / 55 \%$ and in the lecture group $44 / 9 \%$ and had the highest rate. But the treatment was not associated with length of hair, it also shows the importance of personal hygiene rate of Pediculosis treatment [33]. In this Rafeie between prevalence and length of hair was a significant difference $(001 / 0>P)$ [32]. Farzinnia study between infection with head lice and personal hygiene by students with Fisher's exact test between favorable and unfavorable appearance of head lice infestation was significantly correlated $(05 / 0>P$ [31]. In a survey conducted Rafinejad in the city of infected people in schools, health educator tenth per cent while the proportion of schools lack health educator $1 / 7$ this difference was statistically significant.

Given that the study of interfering factors listed in the two groups were similar, can be a strong anti-lice shampoo stating that the training was effective in the treatment. Other ancillary results obtained in this study showed that most were first-grade group (21/8 First grade \%), Rafinejad et al. study highest infection rates in the first grade $7 / 1 \%$ and the lowest in fifth grade $9 / 0 \%$, respectively. And there was no significant difference in educational levels and rates $(0 / 329=\mathrm{P})$. But the study Farzinnia between the contamination in different stages of education, and there is a direct relationship pediculosis capitis $(0 / 05>\mathrm{P})$ and the highest infection rate in the fourth grade and fifth, respectively [34].

Study trustee rights et al. found that there was no correlation between educational levels and extent of contamination [35]. According to the results most people with uneducated mothers $34 / 6 \%$ Dashtndama highest level of education the father of $33 / 6 \%$ were secondary and higher secondary.

Tall et al. study results were almost the same infection rate of students whose parents were illiterate, were higher. The infection rate in students whose mothers were illiterate and diplomat, respectively $21 / 8 \%$ and $3 \%$ respectively. Similarly, the rate of infection in schoolchildren whose father was illiterate and diplomas, $22 / 2 \%$ and $8 \%$ respectively. There was a significant relationship between parental education and children pollution $(0 / 004>\mathrm{P}$ and $0 / 001>\mathrm{P})$ [31]. Also Farzinnia of head lice infestation in the study had no significant relationship with father's education, while in this study, mothers it can be said that there were more illiterate mother's education plays a more lice. In this Farzinnia also highly significant association was observed between the proportion of head lice infestation and maternal education. The highest infection rate was illiterate mothers $(0 / 05>\mathrm{P})$. Also infected students in the study Rafinejad average family in $59 / 7 \%$, respectively. In this study, the average number of family members $4 / 05 \pm 1 / 75$ is [32] In this Farzinnia highest proportion of households with head lice infestation in the next ten or older, the difference could be due to the location study [34] and the study Rafinejad rural population was under investigation father atom. $20 / 8 \%$ unemployed, three hundred to six hundred dollars in terms of revenue most cases $40 / 4$ percent. Father's occupation and the treatment did not exist. [32] Rafeie study also $22 / 8 \%$ of the pupils that their father was unemployed, had Pediculosis contamination and pollution and the relationship between the father's occupation was significant [31]. Farzinnia more than pollution on the floor with fathers are unemployed or workers, but the difference was not significant [33]. the trustee rights as fathers and parental education was associated with the incidence of Pediculosis [34]. Finally, the results of this study showed that the role of education for elementary school girls with Pediculusis to learn how to use permethrin lice shampoo and eventually Pediculosis treatment is more effective than lecturing This result suggests that the attention to health and proper education and training through role playing students could be motivated Is rooted in this cause, by doing this exercise student self-efficacy directly related to his performance, magnified and those who consider themselves very efficient, in addition to a successful performance, improve their selfconfidence can and as a result feel more satisfied with their life.

According to the research findings we recommend that in school 
Citation: Toosi TS (2017) Comparing Role Playing and Lecture Training in Use of Permethrin Shampoo, On Pediculosis Treatment of Elementary School Girls. J Health Educ Res Dev 5: 241. doi: 10.4172/2380-5439.1000241

Page 5 of 5

health education programs, dynamic and effective methods such as role playing, According to health behavior change goals that the active participation of learners in the learning process and also affordable raised was used. Given the prevalence of Pediculosis in some schools, it is recommended [35-39]. The role of anti-lice shampoos used to use education to better results in the treatment of head lice in schools obtained. So according to our findings, the role of each of the variables in the prevalence of Pediculosis having health educators in schools to monitor the health of students, To the effect of teaching through videos by title and Also compare two methods of training slides and animations for the treatment of Pediculosis be examined.

\section{Acknowledgments}

Deputy hereby University of Medical Sciences, School of Nursing and Midwifery Professors Iranshahr, Iranshahr city education authorities and schools, as well as Dear students that helped us in conducting this study is gratitude.

\section{References}

1. Safie MH (2005) The prevalence survey Head Lice Infestation in among primary school Eslamshar Area. Medical entomology and vector control. Master of Sciences Thesis, Tehran University of Medical Sciences, School of Public Health.

2. Zaiim M, Seyadi Rashti SMA, Saebi A (2007) The Principal Medical Entomology. 3rd edn. Tehran: Tehran University Publications.

3. Nutanson I, Steen CJ, Schwartz RA, Jamiger CK (2008) Pediculos humanus capitis: an update. Acta Dermatovenerop Alppanonica Adriat 17: 147-154.

4. BuczekA, Markowska-Gosik D, Widomska D, Monika Kawa I (2004) Pediculosis capitis among school children in Urban and rural areas of eastern Poland. Eur J Epidemiol 19: 491-495.

5. Jahnke C, Bauer E, Feldmeier H (2008) Pediculosis capita in childhood: epidemiological and socio-medical results from screening of school beginners. Gesundheltswesen 70: 667-673.

6. Catalá S, Junco L, Vaporaky R (2005) Pediculus capitis infestation according to sex and social factors in Argentina. Rev Saúde Pública 39: 438-443.

7. Borges R, Silva JJ, Rodrigues RM, Mendes J (2007) Prevalence and monthly distribution of head lice using two diagnostic procedures in several age groups in Uberlândia, State of Minas Gerais, Southeastern Brazil. Revista da Sociedade Brasileira de Medicina Tropical 40: 247-249.

8. Rios SM, Fernandez JA, Rivas F, Saenz ML, Moncada LI (2008) Pediculosis prevalence and associated risk Factors in a nursery school, Bogota, Colombia. Biomedica 28: 245-251.

9. Leung AK, Fong JH, Pinto R (2005) A Pediculosis capitis. J Pediatr Health Care 19: $369-373$

10. Oğuzkaya Artan M, Zeynep Baykan A, Koç N (2006) The prevalence of pediculus capitis in students of eight primary schools in the rural area of the Kayseri province. Turkiye Parazitol Derg 30: 112-114.

11. Ebomoyi EW (1994) Pediculosis capitis among urban school children in llorin Nigeria. J National Med Assoc 86: 861-864.

12. Huh S, Ki-Soo P, Doon Lee S, Kim KJ, Kim NH (1993) Prevalence of head Louse infestation in primary school children in Kangon- do Korea. Korea $J$ Parasitol 31: 67-69.

13. Al-Maktari MT (2002) A study of pediculosis capitis among primary schoo children in Delhi. Department of Community Medicine, Maulana Azad Medical College, Delhi. Indian J Med Sci 56: 449-452.

14. Hansen RC (2004) Overview: the state of head lice management and control. Am J Manage Care 10: 260-263.

15. Shahrake G, Azizy K, Yosefe A, Farardi M (1999) Epidemiology of head Lice infestation in primary school children at Yasoj. Journal of Yasoj University of Medical Sciences 23: 32-37.

16. Ormozde H (1994) Medical parasitology. Tehran: Sajed Publisher.
17. Siros M (1991) Comprehensive medical insectology. Tehran: Tehran University Publisher.

18. Burgess IF (1991) Human Lice and their management: Advances in parasitology. Academic Press Limited, Published by Elsevier 36: 271-342.

19. Suleman M, Fatima T (1998) Epidemiology of head Lice infestation in school children at Peshawar Pakistan. J Tropical Med Hygiene 91: 323-332.

20. Sciscione P, Kvause-Parello CA (2007) No-nit: polices in school: time for change. J Sch Nurs 23: 13-20.

21. Khalkhal M, Mozafar M (2000) Plan to combat head lice in the village of Bandar Anzali Koluyur Health Center, Gilan University of Medical Sciences.

22. Atayi B, Sadri GH (2001) Joey Abad district of pediculosis. Eighth Congress of Infectious and Tropical Diseases, Tehran.

23. Saryazdi S (1998) Head lice in children should not be forgotten. Teb and Tazkieh, pp: 22-26.

24. Akbarzadeh K, Nateghpur M (2001) Prevalence of girls in primary schools in the city of Iranshahr, Iran autumn of Proceedings of the Third Congress of Medical Parasitology, Sari.

25. Daily Med (2013) NIX (permethrin) Shampoo. Daily Med Current Medication Information. US National Library of Medicine: The Association. c. 1993-2013 (Updated 2012 November 26; Cited 2013 December 05). Available from: http:// dailymed.nlm.nih.gov/dailymed/lookup.cfm?setid=8bc95ef1-ea25-4ae7-a6e457 e3e300a2c

26. Dinapoli JB, Austin RD, Englender SJ, Gomez MP, Barrett JF (1988) Eradication of head lice with a single treatment. Am J Public Health 78: 978-980.

27. Mathias RG, Huggins DR, Leroux SJ, Proctor EM (1984) Comparative trial of treatment with priodern lotion and Kwellada shampoo in children with head lice. Can Med Assoc J 130: 407-409.

28. Brandenburg K, Deinard AS, Dinapoli J, Englander SJ, Orthoefer J, et al. (1984) $1 \%$ Permethrin Cream rinse VS $1 \%$ Lindane shampoo in treating Pediculosis capitis. Am J Dis Child 140: 894-896.

29. Mashhad University of Medical Science. Kalat Health Center

30. Khakbazan F, Gamshidi F (2008) Comparison of two teaching methods (lecture training package), the girls' knowledge about adolescent health. Journal of Nursing and Midwifery, Tehran University of Medical Sciences (Hayat) 14: 41-48.

31. Rahmani KH (2009) Comprehensive Textbook of Public Health, pp: 24-87.

32. Hezaveie M, Taghdisi M, Hakak M (2006) Three methods of lecture, role playing games on the knowledge and practice of nutrition counseling in adolescent female students' pace of development in medical education 2: 126-133.

33. Knowles C, Kinchington F, Erwin J, Peters B (2001) A Randomized controlled trial of the effectiveness of combinig video role play with traditional methods of delivering undergraduate medical education. Sex Transm Infect 77: 376-380.

34. Margalit A, Glick S, Benbassat J, Cohen A, Katz M (2005) Promoting a biopsychosocial orientation in family practice: effect of two teaching programs on the knowledge and attitudes of practising primary care physicians. Medical Teacher 27: 613-618.

35. MacLaren J, Cohen L, Larkin K, Shelton E (2008) Training nursing students in evidence-based techniques for cognitive-behavioral pediatric pain management. The Journal of Nursing Education 47: 351-358.

36. Rafiei A, Kasiri H, Mohamadi Z, Haghi H (2009) Head lice and related factors in primary school students in Ahwaz girls in 1386-1385. Journal Infectious Disease related to Infectious Disease Specialists 4: 41-45.

37. Rafi-nejad J, Norelahi A, Javadian A, Kazem-nejad A (2006) Epidemiology of head lice and its effective Vfaktvrhay elementary students AMLASH city, province 2003-1383. Iranian Journal Epidemiology 1: 51-63.

38. Farzinnyia B, Hanefi M (2003) Epidemiology of head lice in primary school girls in Qom. Hormozgan University of Medical Sciences, pp: 108-110.

39. Motevali F, Sharif M, Sedaghat M, Gholami SH (1999) Amount of head lice in primary school students in 1998-77 Sari city. Journal of Mazandaran 9: 43-48. 